\title{
Alternative techniques for failure of conventional inferior alveolar nerve block
}

\author{
Choi Ryang Lee', Hoon Joo Yang ${ }^{1,2}$ \\ 'Department of Oral and Maxillofacial Surgery, School of Dentistry, Seoul National University, Korea \\ ${ }^{2}$ Orthognathic Surgery Center, Seoul National University Dental Hospital, Korea
}

\begin{abstract}
Successful local anesthesia in dental treatment is the most important prerequisite for pain control of patients. However, unlike that in the maxilla, it is difficult to administer local anesthesia in the mandible, and the success rate of conventional inferior alveolar nerve block (IANB) is only $80-85 \%$. It is attributed to various causes such as anatomical variations, extreme anxiety, and technical errors; thus, various alternatives have been devised to improve this. We will analyze the causes of failure in conventional IANB and examine various alternatives that can be applied in these cases.
\end{abstract}

Keywords: Anatomical Factor; Anesthetic Technique; Inferior Alveolar Nerve Block; Patient Factor; Technical Factor.

This is an Open Access article distributed under the terms of the Creative Commons Attribution Non-Commercial License (http://creativecommons.org/licenses/by-nc/4.0/) which permits unrestricted non-commercial use, distribution, and reproduction in any medium, provided the original work is properly cited.

\section{INTRODUCTION}

Pain control through local anesthesia accompanies various dental treatments including oral surgery, endodontic treatment, periodontal treatment, and prosthetic treatment. It is a prerequisite in the reduction of patient's discomfort and completion of dental procedures, and many patients prefer a dentist who provides painless dental treatment [1].

The mandible mainly uses block anesthesia instead of infiltration anesthesia due to close bone mineral density, limited access to the inferior alveolar nerve, and anatomical variation [2]. However, the success rate of conventional inferior alveolar nerve block (IANB) is only 80-85\% [3]. As a result, various anesthetic methods have been devised to replace conventional IANB. For successful local anesthesia, the clinician needs to be familiar with the alternatives and fully understand each feature, indication, and complication. Therefore, this study will present the considerations to avoid failure of conventional IANB and various alternatives.

\section{CONSIDERATIONS TO AVOID FAILURE OF CONVENTIONAL IANB}

For the success of conventional IANB, anatomical, patient, and dentist's technical factors must be fully considered.

\section{Anatomical factors}

\subsection{Determination of the insertion point considering the location of the mandibular foramen}

IANB is a method of delivering anesthetic solution into the pterygomandibular space bounded by the anterior

Received: May 20, 2019 • Revised: June 24, 2019 • Accepted: June 26, 2019

Corresponding Author: Hoon Joo Yang, Orthognathic Surgery Center, Seoul National University Dental Hospital, 101 Daehakro, Jongno-gu, Seoul 03080, Korea Tel: +82-2-2072-4827 Fax: +82-2-766-4948 E-mail: didgnswn@hanmail.net

Copyright(c) 2019 Journal of Dental Anesthesia and Pain Medicine 
buccinator muscle, posterior parotid gland, upward lateral pterygoid muscle, internal medial pterygoid muscle, and external mandibular ramus $[4,5]$. The inferior alveolar nerve, inferior alveolar vein, and inferior alveolar artery, which form the inferior alveolar neurovascular bundles among organizations in the pterygomandibular space, generally have common anatomical patterns $[6,7]$. The inferior alveolar neurovascular bundles are located posterolateral of the lingula tip. Inferior alveolar vessels are located posterior or posterolateral to the inferior alveolar nerve, which is generally located at the forefront, while inferior alveolar veins are located at the rearmost outward $[5,6,8,9]$.

For a complete IANB, the anesthetic solution must be delivered as close to the mandibular foramen as possible. The mandibular foramen resides in the sulcus colli, a spooned-out bony depression inside the mandibular ramus $[4,5]$. The mandibular foramen is located posterior to the midline of mandibular ramus [10-16]. Thangavelu et al. reported that the mandibular foramen is $2.75 \mathrm{~mm}$ posterior to the midpoint of the anteroposterior width of the ramus, $3 \mathrm{~mm}$ above the midpoint of the sigmoid notch and inferior border height at the level of occlusal plane of lower molars, and $19 \mathrm{~mm}$ from the coronoid notch [11]. The anterior border of the sulcus colli is the crista endocoronoidea, a thick bony protrusion that prevents the mechanical injury of the inferior alveolar nerve by needle as well as the lingula $[6,8]$. Considering that the ideal anesthetic solution injection point is directly superior to the lingula, the crista endocoronoidea is the site where the needle tip should be located [6]. Additionally, as the lingula is attached by the sphenomandibular ligament, a dense fibrous band of tissue that prevents anesthetic solution from spreading in case the anesthetic solution is injected just below the lingula, the needle tip should be placed above the tip of the lingula [6,8,17-21]. Moreover, due to the sphenomandibular ligament, a relatively low proportion of loose areolar tissue is distributed in the pterygomandibular space at the height of the lingula, and the ratio of loose areolar tissue increases in the upward direction. It is recommended to insert the needle through the loose areolar tissue for minimum resistance, reduced likelihood of damaging important structures, and reduction of patient's discomfort during the IANB; thus, the insertion point should be located above the lingula [6].

\subsection{Anatomical variations of IAN}

Variations of normal anatomy, such as communication among mandibular nerve branches, can cause local anesthesia failure [22-25]. Desantis and Liebow have described anatomical variations that may hinder the success rate of IANB, including the presence of the accessory mylohyoid nerve, bifid mandibular nerve, and retromolar foramen and contralateral innervation of the anterior teeth $[2,26]$. The nerve to the mylohyoid muscle generally follows the anteroinferior course of the medial side of the mandibular ramus but provides accessory innervation to the mandibular teeth when part of the course of the nerve is an intra-osseous component [17,27-30]. Furthermore, the long buccal nerve and great auricular nerve, which travel through the retromolar foramina, can provide additional innervations to the mandibular teeth $[31,32]$. If an accessory innervation is placed, the pain cannot be resolved by repeating IANB. This symptom can be diagnosed when the patient develops numbness of the lower lip after IANB but is still responds sensitively when stimulated, which is especially common in the mandibular molars [4]. The bifid mandibular nerve develops with a prevalence of $0.35-1 \%$, attributed to the anatomical variations of the inferior alveolar nerve in the development of mandibular bone through the intra-membranous ossification. The most problematic type of the bifid mandibular nerve is a case of two independent mandibular foramina with a portion of inferior alveolar nerve entering both simultaneously [17,33-36].

\section{Patient factors}

\subsection{Psychological factors}

Extreme anxiety and fear of the patient are often major causes of anesthesia failure. In terms of the neuro- 
physiological perspective, even if nerve conduction is blocked, the patient may feel exaggerated or imagined pain when hearing the handpieces $[4,17,37]$. To resolve this, it is helpful to discuss with the patient about the fear of anesthesia, and if necessary, minimal sedation using nitrous oxide can be considered [4,37].

\subsection{Inadequate mouth opening}

The inferior alveolar nerve travels along the medial wall of the mandibular ramus. When mouth opening is inadequate, the nerve is relaxed, away from the lingula tip where the anesthetic solution is injected; thus, the effect of IANB does not work efficiently. Therefore, when IANB is performed, it is necessary to let the patient open the mouth wide so that the inferior alveolar nerve runs as close to the medial wall of the ramus as possible. For this reason, patients with trismus require the use of closed-mouth block anesthesia $[38,39]$.

\subsection{Skeletal patterns}

For successful IANB, extraoral landmarks, such as degree of ramal flaring and height and width of the mandibular ramus as well as intraoral landmarks should be considered $[17,40]$. You et al. reported that the IANB failure rates were significantly higher in the retrognathic mandible $(14.5 \%)$ than in the normal mandible $(7.3 \%)$ and prognathic mandible $(9.5 \%)$ [41]. It is because the distance from the mandibular foramen to the condylar tip is significantly shorter in the retrognathic group, and accordingly, the position of the mandibular foramen is higher in the retrognathic group than that in the normal group. As a result, when the needle is inserted above the occlusal plane with a conventional IANB method, anesthetic solution is infused inferior to the mandibular foramen, resulting in high failure rates. Moreover, in the retrognathic group, insufficient mouth opening due to short condyle length is considered to be the cause of inappropriate IANB [38,41]. In contrast, since the mandibular foramen is located lower in patients with prognathic mandibles than that in the normal group, anesthetic solution can be infused superior to the mandibular foramen. In addition, sufficient mouth opening enables easy identification of anatomical structures [41]. Keros et al. also reported that the location of the mandibular foramen was lower in patients with successful IANB [42]. Therefore, in patients with retrognathic mandibles, anesthetic solution should be infused at a higher point, and Gow-Gates and Akinosi methods that do not depend on the position of the mandibular foramen can be considered [41].

\subsection{Local pathological changes such as infection and inflammation}

If there is an infection in the mandibular nerve branch or pterygomandibular space, it becomes histologically acidic, which may interfere with the onset of anesthesia [43]. The failure rates of IANB in the mandibular posterior teeth with irreversible pulpitis are extremely high at $30-81 \%$ [44-47], which results from activation and sensitization of the nociceptors and stimulation of a greater number of nerve fibers [48-51]. Therefore, the risk of IANB failure can be reduced by depositing the anesthetic solution as far from the infected area as possible.

\section{Technical factors of the clinician}

\subsection{Intravascular injection}

Since the inferior alveolar vessels, especially inferior alveolar veins, are located the most posterolaterally among the components of the inferior alveolar neurovascular bundle and located outside of the lingual and the protective shadow cast by the crista endocoronoidea, it is more exposed to trauma from an inserting needle when IANB is performed [6]. Intravenous injection should be prevented through accurate aspiration before anesthetic solution injection. After the needle tip is inserted and comes in contact with the bone, it must be withdrawn 1-2 $\mathrm{mm}$ before aspiration because the inferior alveolar vein may be pinned to the bone during bone contact, resulting in a false-negative aspiration response $[4,6]$.

\subsection{Haste}

Malamed et al. have recommended that onset of 
anesthesia in IANB is within $3-5$ min and that the time is complied before starting the treatment $[3,38]$. In contrast, waiting for $>5 \mathrm{~min}$ after IANB does not increase the success rate of anesthesia [10].

\subsection{Improper needle placement}

Penetrating the needle tip forward or backward excessively beyond the target area is a common mistake by clinicians [43]. The needle should be inserted to a precise depth of 20-25 $\mathrm{mm}$ to the pterygotemporal depression between the pterygomandibular raphe and coronoid notch [3]. This depth was determined by the distance from the anterior border of the ramus to the midpoint of the mandibular foramen $(19 \mathrm{~mm})$, considering that the IAN may move about $4 \mathrm{~mm}$ posteriorly when a patient opens the mouth [11]. Additionally, it was reported that when injected into one-fourth of the ramus anteriorly, the success rate was lower than that into three-fourths of the ramus posteriorly, resulting in 3.94 times higher need for additional anesthesia [10].

\section{ALTERNATIVES FOR CONVENTIONAL IANB}

\section{Repeat IANB}

Repeat injection has been described as the first option when the initial injection is unsuccessful and may be effective in some cases. On the contrary, Kanna et al. reported a success rate of repeat IANB to be as low as $32 \%$ [52]. Repeated injections in the same area can lead to post-injection pain and even trismus [3].

\section{Buccal infiltration}

Simpson et al. have reported a success rate of $24-38 \%$ in the mandibular teeth with irreversible pulpitis in the case of buccal infiltration of $1.8 \mathrm{~mL}$ with $4 \%$ articaine with epinephrine after IANB failure [53]. Kanaa et al. have reported a success rate of $84 \%$ for additional buccal infiltration with articaine after IANB failure, which was significantly higher than that in intraligamentary injection with $2 \%$ lidocaine with epinephrine $(48 \%)$ or repeat
IANB (32\%) [52]. Anesthetic solution used for buccal infiltration is known to be more effective with $4 \%$ articaine than $2 \%$ lidocaine [54].

\section{Intraligamentary injection}

Intraligamentary injection is performed by spreading a local anesthetic solution to the cancellous medullary bone surrounding the teeth through the periodontal ligament using high injection pressure. It is the most commonly used method after IANB failure in the treatment of mandibular posterior teeth with irreversible pulpitis [33]. While the use of special syringes and needles is simpler, it is equally effective with a standard $27-\mathrm{G}$ needle. The clinician inserts the needle at the mesiobuccal aspect of the root and advances it until maximum penetration is achieved. At this time, keeping the bevel toward the root makes it easier to be penetrated [55]. Afterward, approximately $0.2 \mathrm{~mL}$ of anesthetic solution per root is injected slowly under pressure to prevent pain and extrusion of the teeth [56].

Walton and Abbot reported a success rate of $63 \%$ in the first intraligamentary injection and $92 \%$ in the reinjection in the IANB failure group for endodontic procedures [57], while Smith et al. reported a success rate of $93 \%$ in intraligamentary injection after IANB failure [56].

Since intraligamentary injection has a shorter onset of anesthesia compared to IANB and requires only a small volume of local anesthetic solution, it rarely has the risk for systemic toxicity and nerve damage, and there is much lesser pain on injection $[58,59]$. It also prevents possible rupture, vascular trauma, and excessive bleeding potentially occurring with IANB in patients with bleeding tendency, such as hemangioma [60], and cardiovascular disturbance, such as tachycardia, is less likely to occur [61,62]. In contrast, intraligamentary injection has an anesthesia duration as short as 30-45 $\mathrm{min}$ [58]. Malamed recommended not to perform intraligamentary injections in inflamed or infected periodontal sites [63]. Antibiotic prophylaxis should be considered as there is a risk of bacteremia and bacterial endocarditis due to intraliga- 
mentary injection even when administered to a healthy periodontal tissue [64]. As enamel hypoplasia or hypomineralization of the permanent teeth adjacent to the injection site has been reported, it is not recommended for primary teeth [65].

\section{Intraosseous (IO) anesthesia}

IO anesthesia, which was first published in 1910 [66], was not widely used initially as a rejection of drilling on the cortical bone. However, frequency of its use has increased with the introduction of specialized equipment for IO anesthesia such as the X-tip and Stabident systems. It can also be implemented with standard dental instruments [67]. The clinician infiltrates the gingiva in the area of penetration with $0.2 \mathrm{~mL}$ anesthetic solution and gently drills at $5 \mathrm{~mm}$ apical to the buccal papilla until the cancellous bone is reached. Afterward, a 27- or 30-G needle is inserted into the cortical bone to administer 0.2-0.5 $\mathrm{mL}$ anesthetic solution. There is immediate onset of anesthesia, and anesthesia with vasoconstrictor has a duration of about $60 \mathrm{~min}$, while anesthesia without vasoconstrictor has a duration of 15-30 min [58,68-70]. When IO injection was performed after IANB failure, success rates of $66^{-}$ $91 \%$ were reported, which were significantly higher than those in repeat IANB at 32\% and intraligamentary injection at $48 \%[52,71,72]$. Administration of an IO injection of $1.8 \mathrm{~mL}$ of $2 \%$ lidocaine with 1:100,000 epinephrine may cause an increase in heart rate in approximately $60 \%$ of patients. Therefore, injections without epinephrine such as 3\% mepivacaine without a vasoconstrictor should be used in patients with cardiovascular disease $[68,69]$.

IO anesthesia should be avoided in the case of extensive periodontal disease or acute periapical infection as a fistula may form. IO anesthesia is difficult to be applied to thick cortical plates such as distal to the mandibular second molar or in the case in which the roots of teeth are so close that they preclude clear access to the interdental trabecular bone [63].

\section{Intrapulpal injection}

Since intrapulpal injection achieves anesthesia as a result of pressure, not as a result of the local anesthetic solution, it also has the same effect when performed using saline solution. While this method has an advantage of rapid onset of anesthesia, it has a low indication as it is only available for endodontic procedures with exposed pulp [38].

\section{Gow-Gates mandibular nerve block}

The objective of Gow-Gates mandibular nerve block is to administer the local anesthetic solution to the neck of the condyle near the mandibular branch, the superior nerve of the inferior alveolar nerve [4]. As the intraoral landmark for anesthesia, the external oblique ridge of the anterior surface of the ramus, coronoid process, and temporalis muscle, which attaches to the coronoid process, are palpated. The temporalis muscle must be missed when inserting the needle. The syringe barrel is placed in the contralateral mandibular canine or premolars while the patient keeps the mouth open as wide as possible, and the needle tip should be inserted just below the mesial cusp of the maxillary second molar. It penetrates parallel to the imaginary line connecting the intertragic notch and corner of the mouth and is advanced slowly until it comes in contact with the neck of condyle. Bone contact happens at an average depth of $25 \mathrm{~mm}$. Injection should not be performed before the needle tip comes in contact with the bone, and in case, the needle shall be redirected until it comes in contact the neck of the condyle. After bone contact, withdrawal $1 \mathrm{~mm}$ and aspiration are followed by administration of $1.8 \mathrm{~mL}$ cartridge. Patient should keep their mouths open for at least $20 \mathrm{~s}$ after the injection is performed so that the mandibular branch can be positioned closer to the injection site $[4,73]$. Gow-Gates mandibular nerve block anesthetizes the inferior alveolar nerve and branches (mandibular nerve and mental nerve), lingual nerve, mylohyoid nerve, auriculotemporal nerve, and buccal nerve [3]. Therefore, this nerve block may be useful when IANB fails due to accessory innervation from mylohyoid and auriculotemporal nerves $[4,38]$.

The onset of anesthesia of the Gaw-Gates mandibular nerve block is presented in a range of 5-25 min, which 
is longer than that in IANB [74-77]. Failure and complication rates may be higher than those in IANB methods when performed by beginners [76], while success rates by experienced clinicians are reported to be $>95 \%$ [33]. When the mandibular posterior teeth with irreversible pulpitis were administered with anesthesia in three experiments (2 Gow-Gates mandibular nerve block injections of $3.6 \mathrm{~mL}, 2$ IANB injections of $3.6 \mathrm{~mL}$, and 1 Gow-Gates mandibular nerve block plus 1 IANB injection of each $1.8 \mathrm{~mL}$ ), the success rates were $40 \%$, $44 \%$, and $70 \%$, respectively, showing a significantly good result in a combination of Gow-Gates mandibular nerve block and IANB [44].

\section{Closed-mouth block (Vazirani/Akinosi block)}

As the Akinosi block is an anesthetic method targeting the mandibular branch of the trigeminal nerve similar to the Gow-Gates mandibular nerve block, it is especially useful in case of anatomical variation, including accessory innervation $[4,74,78,79]$. This method is commonly used when there is trismus or difficulty in finding soft tissue landmarks used in conventional IANB procedures $[78,79]$. After palpating the coronoid process while patient's mouth is closed, the needle is inserted at the height of the mucogingival junction of the maxillary posterior teeth between the maxillary tuberosity and coronoid process. The needle should not penetrate the temporalis muscle similar to that in Gow-Gates mandibular nerve block. During anesthesia, the masticatory muscles should remain relaxed, which prevents mastication from interfering with the diffusion of an anesthetic solution by obliterating the pterygomandibular space. The syringe is inserted to a depth of $25 \mathrm{~mm}$ parallel to the maxillary posterior occlusal plane, and at this time, the needle tip is placed between the medial pterygoid muscle and mandibular ramus. There should be no bone contact during insertion. Premature bone contact occurs in most coronoid processes when the insertion point is too far laterally. Aspiration is followed by injection of $1.8 \mathrm{~mL}$ of anesthetic solution [4]. Onset of anesthesia is relatively short with 5-7 $\mathrm{min}$, and the inferior alveolar, lingual, mylohyoid, and buccal nerves are anesthetized [4].

Although possibilities of over-inserting the needle and injuring the vessels in the pterygoid plexus cannot be excluded with no bony landmarks available [80], it is a relatively safe technique that could replace IANB [38].

\section{Modified IANB}

\subsection{Modified IANB by Thangavelu et al.}

After palpating the anterior border of the ramus while the patient is advised to open the mouth fully, the needle is inserted at $6-8 \mathrm{~mm}$ above the midpoint between the upper occlusal plane and lower occlusal plane and 8-10 $\mathrm{mm}$ posterior to the anterior border of the ramus. The needle is advanced until it comes in contact with the medial side of the mandibular ramus, while the syringe barrel is placed at the canine and premolars of the contralateral side, and advanced to the mandibular foramen with continuous bone contact. The insertion depth is $21-24 \mathrm{~mm}$. After the syringe is placed at the contralateral side, $1-1.5 \mathrm{~mL}$ of local anesthetic solution is deposited [74]. This technique has a disadvantage of traumatizing the periosteum of the medial side of the mandibular ramus [22], while it shows a high success rate of $95 \%$, and there are no complications, such as trismus, positive aspiration, hematoma, needle breakage, and nerve injury [74].

\subsection{Arched needle technique}

Since the needle on insertion of the tissues approaches the medial surface of the ramus at an acute angle in conventional IANB, needles are likely to come in contact with the bone too far posteriorly, resulting in complications such as transient facial paralysis $[81,82]$. To improve this, the needle is bent into an arch shape so that the arched needle approaches the medial surface of the ramus almost perpendicularly, which showed the same onset of anesthesia with 3-5 min and success rates of $98 \%$ [81].

\subsection{Modified IANB by Palti et al.}

IANB using two wires was devised to locate the 
mandibular foramen. One wire passes from the mesiobuccal groove and the middle point of the slope of the distolingual cusp of the contralateral mandibular permanent first molar or primary second molar, and the other wire must follow the occlusal plane on the ipsilateral side so that the tip of the orthodontic wire coincides with the center of the mandibular foramen. Coincidence is particularly effective in pediatric patients with $93 \%$ rate compared to $82 \%$ in adults. Although the standard deviation is extremely small even with errors and the actual success rate of anesthesia is presumed to be higher, further clinical studies are needed in the future [2].

While successful local anesthesia is essential for both clinicians and patients in dental treatment, conventional IANB alone has limitations in mandibles that are difficult to anesthetize. Therefore, clinicians should be familiar with various alternatives and be able to use them properly, if necessary.

\section{AUHOR OROIDS}

Choi Ryang Lee: https://orcid.org/0000-0002-7861-8439

Hoon Joo Yang: https://orcid.org/0000-0002-4652-7305

NOTE: The authors have no conflicts of interest to declare.

\section{REFERENCES}

1. Johnson TM, Badovinac R, Shaefer J. Teaching alternatives to the standard inferior alveolar nerve block in dental education: outcomes in clinical practice. J Dental Educ 2007; 71: 1145-52.

2. Palti DG, Almeida CM, Rodrigues Ade C, Andreo JC, Lima JE. Anesthetic technique for inferior alveolar nerve block: a new approach. J Appl Oral Sci 2011; 19(1): 11-5.

3. Malamed SF. Techniques of mandibular anesthesia. In: Handbook of Local Anesthesia. 4th ed. Noida, India, Harcourt Brace. 1997, pp 193-219.

4. Haas DA. Alternative mandibular nerve block techniques: a review of the Gow-Gates and Akinosi-Vazirani closed- mouth mandibular nerve block techniques. J Am Dent Assoc 2011; 142(Suppl 3): 8S-12S.

5. Murphy TR, Grundy EM. The inferior alveolar neurovascular bundle at the mandibular foramen. Dent Pract Dent Rec 1969; 20: 41-8.

6. Khoury J, Mihailidis S, Ghabriel M, Townsend G. Anatomical relationships within the human pterygomandibular space: Relevance to local anesthesia. Clin Anat 2010; 23: 936-44.

7. Roda RS Blanton PL. The anatomy of local anesthesia. Quintessence Int 1994; 25: 27-38.

8. Barker BC, Davies PL. The applied anatomy of the pterygomandibular space. Br J Oral Surg 1972; 10: 43-55.

9. Sicher H, DuBrul E. Oral Anatomy. 6th ed. St. Louis, MO, C.V. Mosby Company. 1975.

10. Ashkenazi M, Sher I, Rackoz M, Schwartz-Arad D. Mandibular block success rate in relation to needle insertion and position: a self-report survey. Eur Arch Paediatr Dent 2014; 15: 121-6.

11. Thangavelu K, Kannan R, Kumar NS, Rethish E, Sabitha S, Sayeeganesh N. Significance of localization of mandibular foramen in an inferior alveolar nerve block. J Nat Sci Biol Med 2012; 3: 156-60.

12. Fujimura K, Segami N, Kobayashi S. Anatomical study of the complications of intraoral vertico-sagittal ramus osteotomy. J Oral Maxillofac Surg 2006; 64: 384-9.

13. Hayward J, Richardson ER, Malhotra SK. The mandibular foramen: its anteroposterior position. Oral Surg Oral Med Oral Pathol 1977; 44: 837-43.

14. Hetson G, Share J, Frommer J, Kronman JH. Statistical evaluation of the position of the mandibular foramen. Oral Surg Oral Med Oral Pathol 1988; 65: 32-4.

15. Ashkenazi M, Taubman L, Gavish A. Age-associated changes of the mandibular foramen position in anteroposterior dimension and of the mandibular angle in dry human mandibles. Anat Rec 2011; 294: 1319-25.

16. da Fontoura RA, Vasconcellos HA, Campos AE. Morphologic basis for the intraoral vertical ramus osteotomy: anatomic and radiographic localization of the mandibular foramen. J Oral Maxillofac Surg 2002; 60: 660-5.

17. Khoury JN, Mihailidis S, Ghabriel M, Townsend G. 
Applied anatomy of the pterygomandibular space: improving the success of inferior alveolar nerve blocks. Aust Dent J 2011; 56: 112-21.

18. Takasugi Y, Furuya H, Moriya K, Okamoto Y. Clinical evaluation of inferior alveolar nerve block by injection into the pterygomandibular space anterior to the mandibular foramen. Anesth Prog 2000; 47: 125-9.

19. Berns JM, Sadove MS. Mandibular block injection: a method of study using an injected radiopaque material. J Am Dent Assoc 1962; 65: 735-45.

20. Garg A, Townsend G. Anatomical variation of the sphenomandibular ligament. Aust Endod J 2001; 27: 22-4.

21. Shiozaki H, Abe S, Tsumori N, Shiozaki K, Kaneko Y, Ichinohe T. Macroscopic anatomy of the sphenomandibular ligament related to the inferior alveolar nerve block. Cranio 2007; 25: 160-5.

22. Khalil H. A basic review on the inferior alveolar nerve block techniques. Anesth Essays Res 2014; 8: 3-8.

23. Thotakura B, Rajendran SS, Gnanasundaram V, Subramaniam A. Variations in the posterior division branches of the mandibular nerve in human cadavers. Singapore Med J 2013; 54: 149-51.

24. Siessere S, Hallak Regalo SC, Semprini M, Honorato De Oliveira R, Vitti M, Mizusaki Iyomasa M, et al. Anatomical variations of the mandibular nerve and its branches correlated to clinical situations. Minerva Stomatol 2009; 58: 209-15.

25. Kim SY, Hu KS, Chung IH, Lee EW, Kim HJ. Topographic anatomy of the lingual nerve and variations in communication pattern of the mandibular nerve branches. Surg Radiol Anat 2004; 26: 128-35.

26. DeSantis JL, Liebow C. Four common mandibular nerve anomalies that lead to local anesthesia failures. J Am Dent Assoc 1996; 127: 1081-6.

27. Stein P, Brueckner J, Milliner M. Sensory innervation of mandibular teeth by the nerve to the mylohyoid: implications in local anesthesia. Clin Anat 2007; 20: 591-5.

28. Arensburg B, Nathan H. Anatomical observations on the mylohyoid groove, and the course of the mylohyoid nerve and vessels. J Oral Surg 1979; 37: 93-6.

29. Jidoi K, Nara T, Dodo Y. Bony bridging of the mylohyoid groove of the human mandible. Anthropol Sci 2000; 108: 345-70.

30. Madeira MC, Percinoto C, das Gracas M, Silva M. Clinical significance of supplementary innervation of the ower incisor teeth: a dissection study of the mylohyoid nerve. Oral Surg Oral Med Oral Pathol 1978; 46: 608-14.

31. Ossenberg NS. Retromolar foramen of the human mandible. Am J Phys Anthropol 1987; 73: 119-28.

32. Tong DC. The great auricular nerve: a case report and review of anatomy. N Z Dent J 2000; 96: 57.

33. Malamed SF. Techniques of mandibular anesthesia. In: Handbook of Local Anesthesia. 5th ed. St. Louis, Mosby; 2004: 227-37.

34. Lew K, Townsend G. Failure to obtain adequate anaesthesia associated with a bifid mandibular canal: a case report. Aust Dent J 2006; 51: 86-90.

35. Sanchis J, Peñarrocha M, Soler F. Bifid mandibular canal. J Oral Maxillofac Surg 2003; 61: 422-4.

36. Langlais RP, Broadus R, Glass BJ. Bifid mandibular canals in panoramic radiographs. J Am Dent Assoc 1985; 110: 923-6.

37. Kaufman E, Weinstein P, Milgrom P. Difficulties in achieving local anesthesia. J Am Dent Assoc 1984; 108: 205-8.

38. Madan GA, Madan SG, Madan AD. Failure of inferior alveolar nerve block: exploring the alternatives. J Am Dent Assoc 2002; 133: 843-6.

39. DuBrul EL. Anatomy of mandibular anesthesia. In: DuBrul EL, Sicher H, eds. Sicher and Dubrul's Oral Anatomy. 8th ed. St. Louis, Ishiyaku EuroAmerica. 1996, pp 273-80.

40. Shields PW. Further observations on mandibular anaesthesia. Aust Dent J 1977; 22: 334-7.

41. You TM, Kim KD, Huh J, Woo EJ, Park W. The influence of mandibular skeletal characteristics on inferior alveolar nerve block anesthesia. J Dent Anesth Pain Med 2015; 15: 113-9.

42. Keros J, Kobler P, Baucic I, Cabov T. Foramen mandibulae as an indicator of successful conduction anesthesia. Coll Antropol 2001; 25: 327-31.

43. Meechan JG. How to overcome failed anaesthesia. Br Dent J 1999; 186: 15-20. 
44. Saatchi M, Shafiee M, Khademi A, Memarzadeh B. Anesthetic efficacy of Gow-Gates nerve block, inferior alveolar nerve block, and their combination in mandibular molars with symptomatic irreversible pulpitis: a prospective, randomized clinical trial. J Endod 2018; 44: 384-8.

45. Nusstein J, Reader A, Nist R, Beck M, Meyers WJ. Anesthetic efficacy of the supplemental intraosseous injection of $2 \%$ lidocaine with 1:100,000 epinephrine in irreversible pulpitis. J Endod 1998; 24: 487-91.

46. Saatchi M, Khademi A, Baghaei B, Noormohammadi H. Effect of sodium bicarbonate-buffered lidocaine on the success of inferior alveolar nerve block for teeth with symptomatic irreversible pulpitis: a prospective, randomized double-blind study. J Endod 2015; 41: 33-5.

47. Tortamano IP, Siviero M, Costa CG, Buscariolo IA, Armonia PL. A comparison of the anesthetic efficacy of articaine and lidocaine in patients with irreversible pulpitis. J Endod 2009; 35: 165-8.

48. Chaudhary P, Martenson ME, Baumann TK. Vanilloid receptor expression and capsaicin excitation of rat dental primary afferent neurons. J Dent Res 2001; 80: 1518-23.

49. Goodis HE, Poon A, Hargreaves KM. Tissue $\mathrm{pH}$ and temperature regulate pulpal nociceptors. J Dent Res 2006; 85: $1046-9$.

50. Hargreaves KM, Keiser K. Local anesthetic failure in endodontics. Endod Topics 2002; 1: 26-39.

51. Stenholm E, Bongenhielm U, Ahlquist M, Fried K. VRland VRL-l-like immunoreactivity in normal and injured trigeminal dental primary sensory neurons of the rat. Acta Odontol Scand 2002; 60: 72-9.

52. Kanaa MD, Whitworth JM, Meechan JG. A prospective randomized trial of different supplementary local anesthetic techniques after failure of inferior alveolar nerve block in patients with irreversible pulpitis in mandibular teeth. J Endod. 2012; 38: 421-5.

53. Simpson M, Drum M, Nusstein J, Reader A, Beck M. Effect of combination of preoperative ibuprofen/ acetaminophen on the success of the inferior alveolar nerve block in patients with symptomatic irreversible pulpitis. J Endod 2011; 37: 593-7.

54. Haase A, Reader A, Nusstein J, Beck M, Drum M.
Comparing anesthetic efficacy of articaine versus lidocaine as a supplemental buccal infiltration of the mandibular first molar after an inferior alveolar nerve block. J Am Dent Assoc 2008; 139: 1228-35.

55. Malamed SF. Supplemental injection techniques. In: Handbook of Local Anesthesia. 4th ed. Noida, India, Harcourt Brace. 1997, pp 220-31.

56. Walton RE, Abbot BJ. Periodontal ligament injection: a clinical evaluation. J Am Dent Assoc 1981; 103: 571-5.

57. Smith GN, Walton RE, Abbott BJ. Clinical evaluation of periodontal ligament anesthesia using a pressure syringe. J Am Dent Assoc 1983; 107: 953-6.

58. Moore PA, Cuddy MA, Cooke MR, Sokolowski CJ. Periodontal ligament and intraosseous anesthetic injection techniques: alternatives to mandibular nerve blocks. J Am Dent Assoc 2011; 142 Suppl 3: 13S-8S.

59. Shabazfar N, Daubländer M, Al-Nawas B, Kämmerer PW. Periodontal intraligament injection as alternative to inferior alveolar nerve block meta-analysis of the literature from 1979 to 2012. Clin Oral Investig 2014; 18: 351-8.

60. Berlin J, Nusstein J, Reader A, Beck M, Weaver J. Efficacy of articaine and lidocaine in a primary intraligamentary injection administered with a computer-controlled local anesthetic delivery system. Oral Surg Oral Med Oral Pathol Oral Radiol Endod 2005; 99: 361-6.

61. Smith GN, Pashley DH. Periodontal ligament injection: evaluation of systemic effects. Oral Surg Oral Med Oral Pathol 1983; 56: 571-4.

62. Claffey E, Reader A, Nusstein J, Beck M, Weaver J. Anesthetic efficacy of articaine for inferior alveolar nerve blocks in patients with irreversible pulpitis. J Endod 2004; 30: 568-71.

63. Malamed SF. Supplemental injection techniques. In: Handbook of Local Anesthesia. 5th ed. St. Louis: Mosby. 2004, pp 256-275.

64. Roberts GJ, Simmons NB, Longhurst P, Hewitt PB. Bacteraemia following local anaesthetic injections in children. Br Dent J 1998; 185: 295-8.

65. Brannstrom M, Lindskog S, Nordenvall KJ. Enamel hypoplasia in permanent teeth induced by periodontal ligament anesthesia of primary teeth. J Am Dent Assoc 
1984; 109: 735-6.

66. Masselink BH. The advent of painless dentistry. Dent Cosmos 1910; 52: 868-72.

67. Replogle K, Reader A, Nist R, Beck M, Weaver J, Meyers WJ. Anesthetic efficiency of the intraosseous injection of $2 \%$ lidocaine (1:100,000 epinephrine) and 3\% mepivacaine in mandibular first molars. Oral Surg Oral Med Oral Pathol Oral Radiol Endod 1997; 83: 30-7.

68. Replogle K, Reader A, Nist R, Beck M, Weaver J, Meyers WJ. Cardiovascular effects of intraosseous injections of 2 percent lidocaine with 1:100,000 epinephrine and 3 percent mepivacaine. J Am Dent Assoc 1999; 130: 649-57.

69. Coggins R, Reader A, Nist R, Beck M, Meyers WJ. Anesthetic efficacy of the intraosseous injection in maxillary and mandibular teeth. Oral Surg Oral Med Oral Pathol Oral Radiol Endod 1996; 81: 634-41.

70. Sam S, Chakorn V, Sirichai K, Chavengkiat S, Natthamet W. Inferior alveolar nerve block by intraosseous injection with Quicksleeper ${ }^{\mathbb{R}}$ at the retromolar area in mandibular third molar surgery. J Dent Anesth Pain Med 2018; 18: 339-47.

71. Nusstein J, Reader A, Nist R, Beck M, Meyers WJ. Anesthetic efficacy of the supplemental intraosseous injection of $2 \%$ lidocaine with 1:100,000 epinephrine in irreversible pulpitis. J Endod 1998; 24: 487-91.

72. Parente SA, Anderson RW, Herman WW, Kimbrough WF, Weller RN. Anesthetic efficacy of the supplemental intraosseous injection for teeth with irreversible pulpitis.
J Endod 1998; 24: 826-8.

73. Gow-Gates GA. Mandibular conduction anesthesia: a new technique using extraoral landmarks. Oral Surg Oral Med Oral Pathol 1973; 36: 321-8.

74. Thangavelu K, Kannan R, Kumar NS. Inferior alveolar nerve block: alternative technique. Anesth Essays Res 2012; 6: 53-7.

75. Malamed SF. The Gow-Gates mandibular block. Evaluation after 4,275 cases. Oral Surg Oral Med Oral Pathol 1981; 5: 463-7.

76. Levy TP. An assessment of the Gow-Gates mandibular block for third molar surgery. J Am Dent Assoc 1981; 103: $37-41$.

77. Jofre J, Munzenmayer C. Design and preliminary evaluation of an extra oral Gow-Gates guiding device. Oral Surg oral Med Oral Pathol Oral Radiol Endod 1998; 85: 661.

78. Vazirani SJ. Closed mouth mandibular nerve block: a new technique. Dent Dig 1960; 66: 10-3.

79. Akinosi JO. A new approach to the mandibular nerve block. Br J Oral Surg 1977; 15: 83-7.

80. Dover WS. The mandibular block injections it sometimes fails. J Dent Assoc South Afr 1971; 26: 373-7.

81. Chakranarayan A, Mukherjee B. Arched needle technique for inferior alveolar mandibular nerve block. J Maxillofac Oral Surg. 2013; 12: 113-6.

82. Parsons-Smith G, Roberts JM. Facial paralysis after local dental anaesthesia. Br Med J 1970; 4: 745-6. 